\title{
HIGH BASDAI SCORES DID NOT REDUCE IMMUNE RESPONSE TO PLANNED YELLOW FEVER PRIMARY VACCINATION IN SPONDYLOARTHRITIS
}

Thays Zanon Casagrande ${ }^{1, \star}$, Ketty Lysie Libardi Lira Machado ${ }^{1}$, Samira Tatiyama Miyamoto ${ }^{1}$, Arthur Dalmaso Pinto ${ }^{1}$, Priscila Costa Martins Rocha $^{1}$, Erica Vieira Serrano ${ }^{1}$, Valquiria Garcia Dinis ${ }^{1}$, Sônia Alves Gouvêa ${ }^{1}$, João Gabriel Fragoso Dias1, Maria Bernadete Renoldi de Oliveira $\mathrm{Gavi}^{1}$, Lidia Balarini da Silva ${ }^{1}$, Ruben Horst Duque ${ }^{1}$, Ana Paula Espíndula Gianordolii ${ }^{1}$, Karine Gadioli Oliveira ${ }^{1}$, Lauro Ferreira da Silva PintoNeto ${ }^{4}$, Elizandra Tomazela Laurenti Polito ${ }^{5}$, Leticia Resende Brandão ${ }^{5}$, Sheila Maria Barbosa de Lima ${ }^{3}$, Emily Hime Miranda ${ }^{3}$, Gisela Freitas Trindade $^{3}$, Maria de Lourdes de Sousa Maia, Ana Carolina Campi-Azevedo², Andréa Teixeira-Carvalho², Vanessa Peruhype-Magalhães², Ismael Artur da Costa-Rocha², Olindo Assis Martins-Filho², Valéria Valim ${ }^{1}$

1.Universidade Federal do Espírito Santo, Vitória (ES), Brazil. 2.Fundação Oswaldo Cruz, Belo Horizonte (MG), Brazil. 3.Fundação Oswaldo Cruz, Rio de Janeiro (RJ), Brazil. 4.Escola de Ciências da Saúde da Santa Casa de Misericórdia, Vitória (ES), Brazil. 5.Sociedade de Reumatologia do Espírito Santo, Vitória (ES), Brazil.

*Corresponding author: thays.zanon@gmail.com

\section{BACKGROUND}

Yellow fever (YF) vaccination might cause a large number of adverse events (AEs) and suboptimal responses in patients with autoimmune diseases (AIDs); however, there have been no studies on 17DD-YF primary vaccination performance in spondyloarthritis group. In 2017, Brazil's yellow fever epidemic triggered the need to vaccinate most people and made this study an opportunity.

\section{MATERIALS AND METHODS}

Prospective noninterventional study accomplished in 2017 assessing safety and immunogenicity of planned 17DD-YF primary vaccination. Adults with spondyloarthritis $(\mathrm{SpA}, \mathrm{n}=51$ ) were enrolled along 38 healthy controls $(\mathrm{HC})$, referred for planned vaccination by a rheumatologist. All had low level immunosuppression or had their biological therapy suspended for a period of 5 half-lives before vaccination. The occurrence of AEs, neutralizing antibody kinetics and seropositivity rates were evaluated at various time points (day 0 [D0], D3, D4, D5, D6, D14, and D28). Bath ankylosing spondylitis disease activity index (BASDAI) scores were evaluated at times D0 and D180.

\section{RESULTS}

The majority (73\%) of SpA patients were in remission or low disease activity, in D0 with a mean BASDAl index of $2.7 \pm 2.1$. In the analysis using the BASDAI score, patients with controlled or active disease (BASDAI $<4$ or BASDAI $\geq 4$ ) presented similar seroconversion profiles according to the plaque reduction neutralization test (PRNT) at D28 (75\% vs. 69\%, $p=0.6$ ), and low seropositivity rates related to $\mathrm{HC}(75 \%$ vs. $96 \%, p<0.05)$ and $(69 \%$ vs. $96 \%, p<0.05)$, respectively. The PRNT titers in the $\mathrm{HC}$ group were $44095 \% \mathrm{Cl}$ (291-665), higher than in the BASDAI < 4 (118, 95\% Cl (72-193), $\mathrm{p}<0.01)$ and BASDAI $\geq 4$ (92, $95 \% \mathrm{Cl}(36-239), p<0.01)$. Seropositivity and PRNT titers were according to BASDAI (Fig. 1). The follow-up showed a drop in BASDAI. In the subgroups analysis, patients with controlled disease did not change BASDAl in D180 $(1.34 \pm 2.05 \mathrm{vs} .2 .29 \pm 0.5$, $p=0.2)$ and those with active disease showed a decrease in disease activity ( $6.31 \pm 1.33$ vs. $4.14 \pm 2.13 p=0.04)$, with $31 \%$ achieving BASDAI < 4. Figure 2 shows BASDAI scores in D0 and D180.

\section{CONCLUSION}

The 17DD YF vaccine is safe for SpA patients, even with disease activity at vaccination time. BASDAI $\geq 4$ did not reduce immune response, and the vaccine might have an immunomodulatory role, by reducing activity in the follow-up. 
Neutralizing Antibody Titers and Seropositivity Rates in Spondyloarthritis Patients Categorized According to the Disease Activity (BASDAI) at Baseline

A

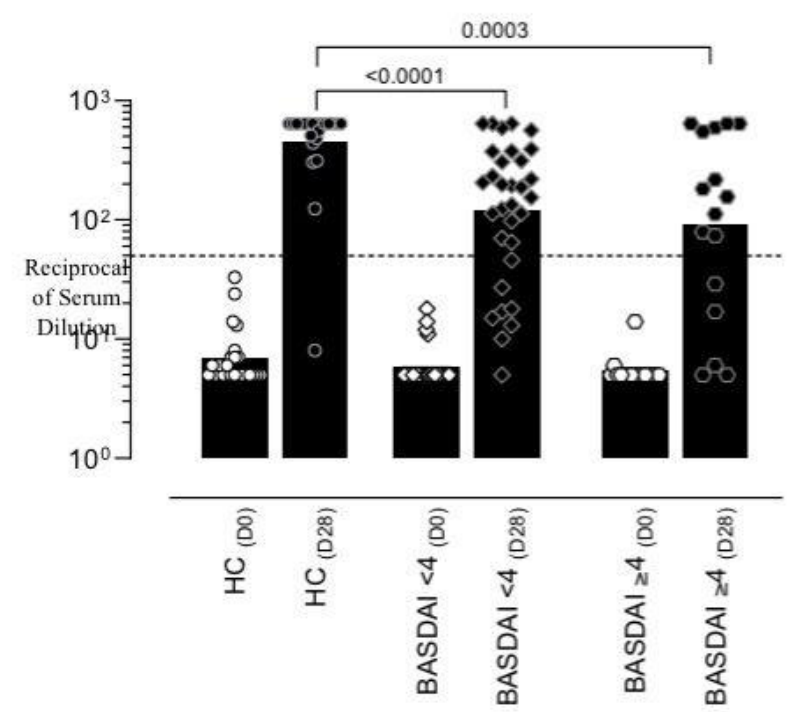

B

PRNT Seropositivity Rates

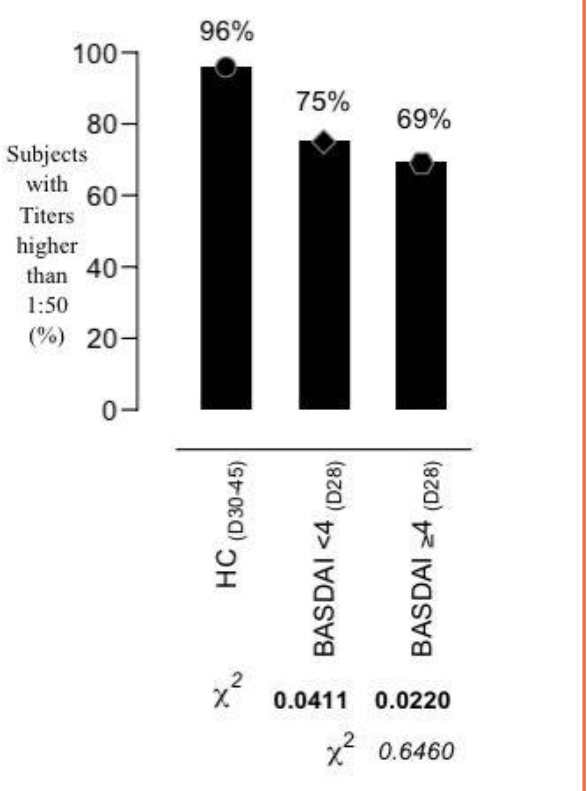

Figure 1. PRNT titers in D0 and D180, according to BASDAI at baseline and seropositivity rates.

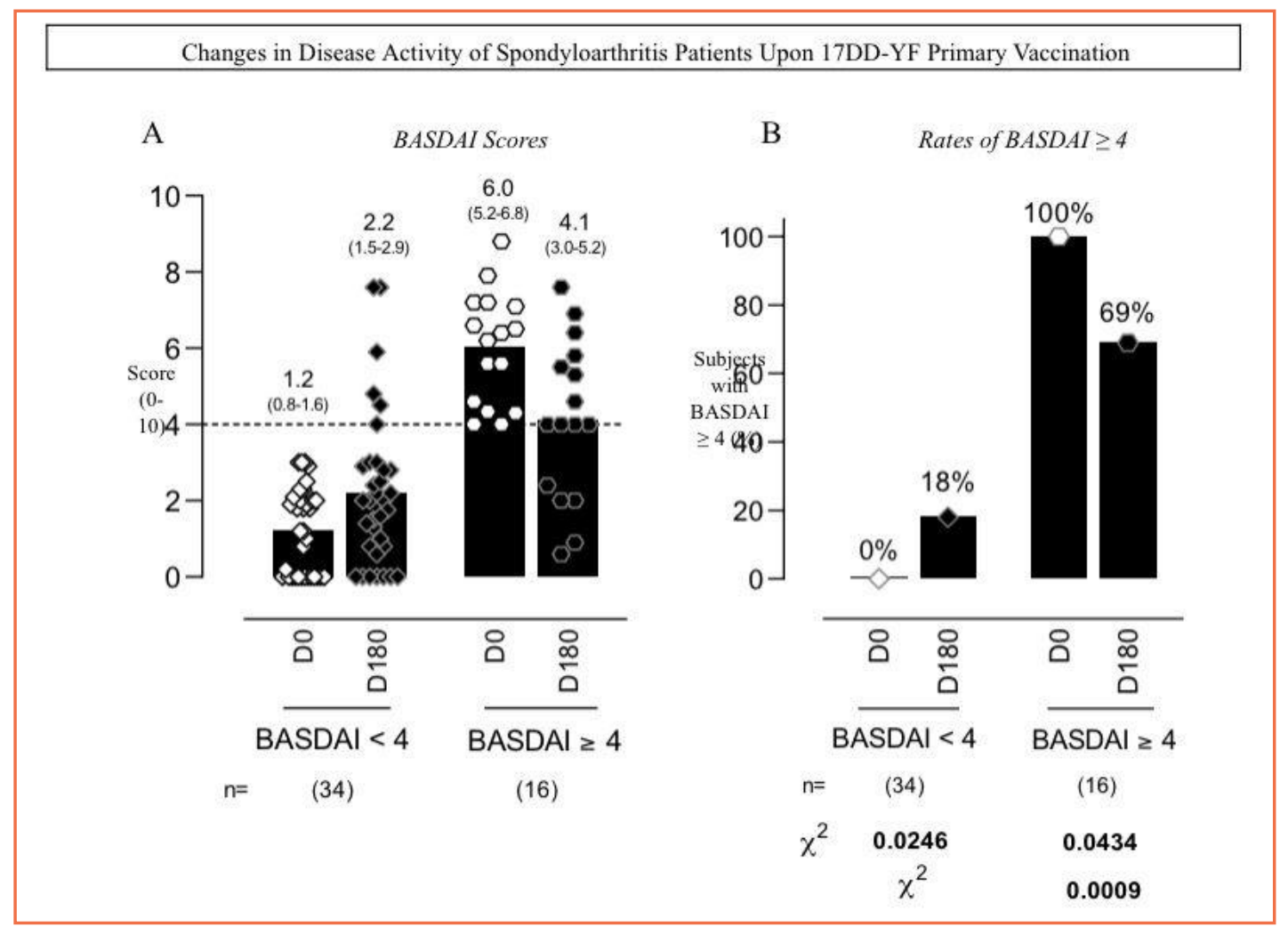

Figure 2. BASDAl scores in D0 and D180 after 17DD-YF primary vaccination. 